\title{
Evaluating Responses of Sugar Beet Cultivars to Fusarium Species in Greenhouse and Field Conditions
}

\author{
Burlakoti $\mathrm{P}^{1}$, Mohamed FR Khan ${ }^{1,2^{*}}$, Rivera $\mathbf{V}^{1}$, Secor GA ${ }^{1}$ and Qi $\mathrm{A}^{3}$ \\ ${ }^{1}$ Department of Plant Pathology, North Dakota State University, USA \\ ${ }^{2}$ University of Minnesota, St Paul, USA \\ ${ }^{3}$ University of Hertfordshire, UK
}

Submission: May 09, 2018; Published: May 30, 2018

*Corresponding author: Mohamed FR Khan, Department of Plant Pathology, North Dakota State University, Fargo, ND 58105, USA, Email: mohamed.khan@ndsu.edu

\begin{abstract}
Fusarium yellows of sugar beet (Beta vulgaris L.) is becoming an important disease in Minnesota and North Dakota in the United States. One of the best ways to manage Fusarium yellows is to develop and use resistant cultivars. Responses of eight sugar beet cultivars to three Fusarium species were determined in the greenhouse and compared to the responses of the same eight cultivars grown in a field already infected by Fusarium yellows. There were significant and appreciable relationships between greenhouse and field studies for responses of eight sugar beet cultivars on Fusarium yellows. The estimated correlation coefficient for area under disease progress curve (AUDPC) between observations in fields and those in greenhouses was $0.987(\mathrm{p}<0.01)$. The mean AUDPC were significantly different among cultivars $(\mathrm{p}<0.01)$ in the greenhouse and in the field studies. Of the cultivars, Van der Have 46177 was the most susceptible, but Crystal R434 the most resistant. Crystal 820, Van der Have 66561, and Beta 4797R were resistant, and Beta 4818R, Seedex Magnum, and Hilleshog 2463Rz were moderately resistant. There was a strong negative relationship between the AUDPC and recoverable sucrose yield in the field experiments and the estimated coefficient of determination was $0.939(\mathrm{p}<0.01)$. It was concluded that greenhouse screening can act as a useful and reliable means to evaluate and select beet germplasms and/or accessions for resistance to Fusarium yellows.
\end{abstract}

Keywords: Fusarium oxysporum; Fusarium graminearum; Fusarium secorum; Area under disease progress curve; Recoverable sucrose.

\section{Introduction}

Fusarium yellows of sugar beet (Beta vulgaris L.) caused by Fusarium oxysporum f. sp. betae was first described by Stewart in 1931 [1,2]. The pathogen has become widespread and an emerging threat to the sugar beet industry especially in North Dakota and Minnesota in the United States (U.S.) [3,4]. The disease has been reported in western sugar beet production states such as Colorado, Nebraska, Wyoming, and Montana [1,5,6]; Michigan Hanson [7]; North Dakota and Minnesota [6,8,9]. Early infection results in death of seedlings $[10,11]$. In North Dakota and Minnesota, the typical foliar symptoms observed include interveinal yellowing of leaves starting with oldest leaves first, occasional yellowing of half of the leaf demarcated by the midrib, followed by leaf necrosis. The outside of roots of infected plants appear healthy; however, transverse sections through the tap roots or lateral roots show a gray or brownish vascular discoloration [12]. The typical discoloration of the tip of the taproot characteristic of Fusarium root rot caused by F. oxysporum f. sp. radicis-betae in Texas where sugar beet is irrigated Harveson \& Rush [13] is not present on infected plants in North Dakota and Minnesota where the crop is rain fed. Fusarium infection causes a significant reduction in sugar yield as a result of reduced root yield and sucrose concentrations $[12,14]$. The disease recently has emerged as a serious problem for sugar beet growers in some areas of the Red River Valley (RRV) in the adjoining states of North Dakota and Minnesota $[4,12]$. Burlakoti et al. [15] reported a new F. species (F. sp. novum) which was formally named $F$. secorum Secor et al. [16] that causes similar symptoms as Fusarium yellows but was named Fusarium decline because of its ability to cause severe disease.

The use of resistance cultivars is an important approach in the management of soil borne Fusarium diseases [17]. Early studies by Bockstahler [5] found wilting resistance to F. oxysporum f. sp. betae in several accessions of sugar beet. American Crystal Sugar Company, one of the largest sugar cooperative in the Red River Valley Khan [18], started a small-scale screening of cultivars for Fusarium resistance in 2005 and showed that cultivars had different levels of resistance to Fusarium spp. [19]. It was observed that a few commercial cultivars widely used in the Red River Valley were highly susceptible to Fusarium spp. Interestingly, some cultivars 
that showed resistance to Fusarium yellows at testing sites in other states were susceptible when grown in limited strip trials and at the Fusarium nursery at Sabin, Minnesota [20]. Hanson et al. [21] also found variability in some of the sugar beet lines to the several individual $F$. oxysporum $\mathrm{f}$. sp. betae isolates collected from different states (Michigan, Oregon, Minnesota, Colorado and Montana of the United States). Rivera et al. [22] and Secor et al. [16] reported the presence of $F$. oxysporum f. sp. betae, F. graminearum, as well as F. secorum infecting sugar beet in the Red River Valley. Identification of cultivars with resistance to Fusarium species present in the Red River Valley will provide useful information for breeders as well as growers. In North Dakota and Minnesota, the available time for field screening is limited and trials need to be done at multiple sites in areas where sugar beet is currently grown and where the disease is present. It will be useful to have a greenhouse methodology that accurately determines which cultivars are resistant to and which are susceptible to pathogenic Fusarium isolates representative of the region. Researchers can then focus on further improving the agronomic characteristics of cultivars that are shown to be resistant to Fusarium spp. in field trials. The objectives of this research were (i) to determine the resistance of sugar beet cultivars in greenhouse conditions to three different Fusarium species - F. secorum, F. oxysporum, and F. graminearum prevalent in the Red River Valley; and (ii) to determine the resistance level of sugar beet cultivars grown in fields with a history of Fusarium yellows; and (iii) to compare the response of the cultivars in the greenhouse controlled conditions with that in the field conditions.

\section{Materials and Methods}

\section{Greenhouse study}

Greenhouse study was conducted to determine the resistance level of sugar beet cultivars to three different Fusarium species ( $F$. secorum, F. oxysporum, and F. graminearum), which are currently prevalent in the Red River Valley [22].

\section{Plant material and growing conditions}

Eight cultivars, Van der Have 46177, Van der Have 66561, Beta 4818R, Beta 4797R, Seedex Magnum, Hilleshog 2463Rz, Crystal 820, and Crystal R434, were grown in the greenhouse for 38 days from emergence. Seeds were sown in $3.8 \mathrm{~cm}$ diameter x $21 \mathrm{~cm}$ deep cone-tainers (Stuewe \& Sons, Inc., Corvallis, OR) filled with Sunshine Mix 1 (Sun Gro Horticulture, Bellevue, WA) amended with 200g of Osmocote 14-14-14 (Scotts Co., Marysville, $\mathrm{OH})$ per 0.76 cubic $\mathrm{m}$ of Sunshine Mix 1 . Two sugar beet seeds were sown in each cone at $2.2 \mathrm{~cm}$ depth. Plants were thinned at the 2-leaf stage leaving one plant per cone-tainer. Plants were grown in the greenhouse with fluorescent light set and maintained for a photoperiod of $16 \mathrm{hd}^{-1}$ and air temperature set and maintained at $27 \pm 2{ }^{\circ} \mathrm{C}$

\section{Isolates and inoculum preparation}

Eight most virulent isolates: four isolates of $F$ secorum (525, 408, 605, and 229b), two isolates of F. oxysporum (218 and 581.121), and two isolates of F. graminearum (581.101 and 578.5b) determined in a pathogenicity study [23], were selected and used to screen the cultivars independently under greenhouse conditions. F. secorum was initially reported as F. sp. novum in Burlakoti et al. [23], Burlakoti et al. [15] and Rivera et al. (2008). Isolates were transferred and grown on freshly made half strength potato dextrose agar (PDA) Burlakoti et al. [23] for 10 days at room temperature with fluorescent light set for a photoperiod of $12 \mathrm{hd}^{-1}$. Hyphal material and spore were harvested by flooding the culture plates with five milliliters of sterile distilled water and scraping the plates with a sterile bent glass rod. The spore suspension was prepared as described by Burlakoti et al. [15].

\section{Inoculation and disease assessment}

Inoculation with eight virulent isolates was done on 38 days old sugar beet seedlings at the 4-6 leaf stage. Seedlings were gently removed from cone-tainers, their roots were washed with sterilized water and then dipped in a suspension of Fusarium conidia for eight minutes. The suspension was thoroughly shaken every minute for uniform distribution of conidia. Roots were inoculated with sterile distilled water as a control. Plants were then transplanted immediately to freshly prepared cone-tainers, as described above, and then kept for two days in a growth chamber where the temperature was set and maintained at $21 \pm 2$ ${ }^{\circ} \mathrm{C}$ to reduce transplanting shock. The plants were subsequently transferred into the greenhouse where temperature was set and maintained at $27 \pm 2{ }^{\circ} \mathrm{C}$. Natural light was supplemented with fluorescent light to extend the photoperiod to $16 \mathrm{hd}^{-1}$.

Three days after transplanting, the oldest two leaves were removed to avoid confusing between yellowness on leaves due to transplanting shock and Fusarium yellows. Plants were grown in the greenhouse for 60 days after inoculation (DAI). Previous study indicated that some isolates did not cause additional vascular discoloration after 35 DAI. As such, inoculated plants were evaluated for $60 \mathrm{DAI}$ in this study. Plants were hand-watered daily and carefully so that there was no splashing of soil or water between different treatments. Plants were individually and independently examined and rated twice weekly for foliar symptoms using a disease severity rating scale of 0-4 similar to Hanson and Hill (2004) with slight modifications where, $0=$ healthy plants, $1=$ plants stunted and wilted with few yellowed leaves (1-24\%); $2=$ chlorosis and necrosis of lower leaves (25-59\%); $3=$ crown becoming dried and brown to black in color, lower leaves dying (60-89\%); and $4=$ death of entire plant (90-100\%). The pathogen was re-isolated from root of inoculated plants for confirmation. Plants that were severely infected were harvested for re-isolation before 60 DAI. The experiment was conducted in a factorial combination of two factors - Fusarium species and cultivars (i.e. a total of 24 treatments) - in as a randomized complete block (RCB) design with three replicates for each treatment. The experiment was conducted in 2006 and repeated in 2007. The cultivars were categorized to different levels of resistance based on mean area under the disease progress curve (AUDPC) value. 


\section{Field study}

Trials were conducted at Sabin, MN (SW Section 10 138-48 (Kurtz TWP), 46 46.500' N 09644 124' W) in 2006 and 2007, with a history of severe Fusarium yellows. Eight cultivars, the same as used in the greenhouse study, were planted using a John Deere MaxEmerge 2 planter (Deere and Company World Headquarters, Moline, Illinois) into plots $3.4 \mathrm{~m}$ wide (6 row with $56 \mathrm{~cm}$ row spacing) and $7.6 \mathrm{~m}$ long on May 18, 2006 and May 11, 2007. Fertilization was applied according to standard recommendation for sugar beet in the region and plots were kept weed free using micro-rates of herbicides recommended for sugar beet [24]. The experimental design was a randomized complete block with four replicates. Plants were naturally infected. Plants were rated for foliar symptoms using the $0-4$ disease severity scale at 10 days interval as described in the greenhouse study. Two infected plants from second and fifth rows were sampled at 10 days interval for confirmation of the pathogens. The middle-two rows of plots were harvested for yield and quality determinations on September 11 in 2006 and September 13 in 2007. Quality analysis was conducted by American Crystal Sugar Company Quality Tare Laboratory, East Grand Forks, Minnesota. Recoverable sucrose yield was determined from net clean root yields and sucrose concentration of harvested sugar beet samples of each treatment after discounting for losses from sugar to molasses and other impurities. Three infected roots from each of the middle two rows were sampled after harvesting to isolate and confirm the pathogen.

\section{Data analysis}

Foliar ratings were first converted to percentages, using the mid-point rule [25], and the foliar severity value for each rating category was then used to calculate area under the disease progress curve (AUDPC). The resistance level of sugar beet cultivars was categorized on the basis of AUDPC values. Test of homogeneity between two repeated experiments was performed before combining the data from the two experiments in 2006 and 2007. This was done by calculating the $F$ ratio between error mean variance of two individual experiments as described by Gomez and\& Gomez [26]. Analysis of variance (ANOVA) for AUDPC, clean beet yield in net tonne per hectare $\left(\mathrm{t} \mathrm{ha}^{-1}\right)$, recoverable sucrose yield in kilogram per hectare ( $\left.\mathrm{kg} \mathrm{ha}^{-1}\right)$, and sucrose concentration (\%) was performed using SAS version 9.1 (Statistical Analysis System, Cary, NC). The least significance difference (LSD) of means at $p<0.05$ was calculated and presented for comparison of different treatment effects. Regression analyses were performed to determine the association between corresponding observations from the greenhouse and field experiments, and to determine the relationship between Fusarium yellows and recoverable sucrose yield ( $\mathrm{kg} \mathrm{ha}^{-1}$ ) and sucrose concentration (\%) in the field experiments. When relating the AUDPC from the greenhouse experiments to those from the field experiments, the measurements of AUDPC from three different species were averaged for individual cultivars in the greenhouse study assuming that the infected fields had a good mixture of identical isolates inoculated with these three species.

\section{Results}

\section{Greenhouse study}

No symptoms of Fusarium yellows were observed on sugar beet plants inoculated with sterile distilled water. Test for homogeneity of variance in AUDPC was not statistically significant $(p>0.05)$. Even though the $F$ ratio between error mean variance of experiments in 2006 and 2007 showed evidence that the homogeneity between the two repeated experiments was tested negative, the residual mean variance was rather small in both years. In fact, the residual mean variance was 0.013 and 0.055 in 2006 and 2007, respectively. The analyses also showed that the effects of sugar beet cultivar, Fusarium species and their interaction combined to account for $99.2 \%$ and $96.2 \%$ of the variance in 2006 and 2007, respectively. This clearly suggested that the control of random variation was satisfactory. Therefore, the observations for AUDPC from two repeated experiments were combined when the ANOVA was conducted.

Table 1: Area under disease progress curve (AUDPC) of Fusarium yellows of sugar beet caused by a $F$. secorum, $F$. oxysporum, and $F$. graminearum during 60 days after inoculation averaged over 2006 and 2007 in greenhouse experiments.

\begin{tabular}{|c|c|c|c|}
\hline \multirow{2}{*}{ Cultivars } & \multicolumn{3}{|c|}{ Area Under Disease Progress Curve } \\
\cline { 2 - 4 } & F secorum & F oxysporum & F. graminearum \\
\hline $\begin{array}{c}\text { Van der Have } \\
46177\end{array}$ & 3365.4 & 2580.1 & 360.3 \\
\hline $\begin{array}{c}\text { Seedex } \\
\text { Magnum }\end{array}$ & 875 & 976.1 & 43.8 \\
\hline Beta 4818R & 790.2 & 940.2 & 41.4 \\
\hline $\begin{array}{c}\text { Hilleshog } \\
2463 \mathrm{Rz}\end{array}$ & 858.7 & 867.7 & 38.9 \\
\hline Crystal 820 & 56.1 & 98.6 & 0 \\
\hline $\begin{array}{c}\text { Van der Have } \\
66561\end{array}$ & 233 & 249.2 & 0 \\
\hline Beta 4797R & 282.9 & 279.9 & 0 \\
\hline Crystal R434 & 18.3 & 19.4 & \\
\hline CV \% & & 9.1 & \\
\hline LSD at 5\%x & & 56.23 & 0 \\
\hline
\end{tabular}

'Least significant differences of means at $p<0.05$.

When data from two years were combined, there were no yearly significant effects between 2006 and 2007 and in the interactions of the year with beet cultivar and/or Fusarium species on AUDPC. The effects of cultivar and Fusarium species and their interactions were all significant $(\mathrm{p}<0.01)$ on AUDPC. With a few exceptions (Seedex Magnum and Beta 4818R), isolates of $F$. secorum and F. oxysporum typically resulted in similar AUDPC on the same cultivars. F. graminearum isolates caused very low or no disease on the cultivars (Table 1). The AUDPC cause by $F$. graminearum was significantly lower than the AUDPC caused by $F$. secorum and F. oxysporum on most sugar beet cultivars. The mean AUDPC of all isolates on Van der Have 46177 was significantly higher than on the other seven cultivars evaluated. Four sugar beet cultivars - Crystal R434, Beta 4797R, VDH 66561, and Crystal 820 
- responded as resistant, three cultivars -Hilleshog 2463Rz, Beta 4818R, and Seedex Magnum -responded as moderately resistant, and one cultivar -Van der Have 46177 -responded as susceptible, to virulent isolates of $F$. secorum and F. oxysporum.

\section{Field study}

Test for homogeneity of variance between 2006 and 2007 was not significant in AUDPC, clean net root yield $\left(\mathrm{t} \mathrm{ha}^{-1}\right)$, recoverable sucrose yield $\left(\mathrm{kg} \mathrm{ha}^{-1}\right)$ and sucrose concentration (\%). When data were combined from two years, there were no significant effects between years and in the interactions of year with beet cultivar on AUDPC. However, the effects of cultivars were significant $(p<0.01)$ on AUDPC. Analyses of combined data from two years showed that there was not a significant interaction effect of year with cultivar on clean net root yield, recoverable sucrose yield and sucrose concentration. However, there were significant effects of season and cultivar on crop performance and quality indicators. Recoverable sucrose yields were significantly higher $(p<0.01)$ in 2006 than in 2007, and sucrose concentrations were significantly higher $(\mathrm{p}<0.01)$ in 2007 than in 2006.

Table 2: The responses of eight sugar beet cultivars to Fusarium yellows, and the impacts of the disease on clean root yield in net tonne per hectare $\left(\right.$ tha $\left.^{-1}\right)$, recoverable sucrose yield in kilogram per hectare $\left(\mathrm{kgha}^{-1}\right)$, and sucrose concentration (\%) based on the fresh root weight averaged over 2006 and 2007 in the field experiments.

\begin{tabular}{|c|c|c|c|c|}
\hline Cultivars & $\begin{array}{c}\text { Area Under } \\
\text { Disease } \\
\text { Progress } \\
\text { Curve }\end{array}$ & $\begin{array}{c}\text { Root } \\
\text { yield } \\
\text { (tha }^{-1} \text { ) }\end{array}$ & $\begin{array}{c}\text { Sucrose } \\
\text { Concentration } \\
\text { (\%) }\end{array}$ & $\begin{array}{c}\text { Recoverable } \\
\text { sucrose } \\
\text { (kgha-1) }\end{array}$ \\
\hline $\begin{array}{c}\text { Van der } \\
\text { Have } \\
46177\end{array}$ & 2771.6 & 24.2 & 12.5 & 2592.1 \\
\hline $\begin{array}{c}\text { Seedex } \\
\text { Magnum }\end{array}$ & 760.6 & 45.7 & 14.5 & 5822.7 \\
\hline Beta 4818R & 693.7 & 45.7 & 14 & 5619.1 \\
\hline $\begin{array}{c}\text { Hilleshog } \\
2463 R z\end{array}$ & 739.5 & 44.2 & 14 & 5371.2 \\
\hline Crystal 820 & 358.7 & 47.2 & 15.4 & 6467.8 \\
\hline $\begin{array}{c}\text { Van der } \\
\text { Have } \\
66561\end{array}$ & 374.1 & 52.9 & 15.2 & 7084.8 \\
\hline Beta 4797R & 306.3 & 50.9 & 14.8 & 6646.5 \\
\hline $\begin{array}{c}\text { Crystal } \\
\text { R434 }\end{array}$ & 221.5 & 58.8 & 14.5 & 7246.5 \\
\hline \begin{tabular}{c} 
CV \\
\hline LSD at 5\%x
\end{tabular} & 129.4 & 5.2 & 0.9 & 745.5 \\
\hline
\end{tabular}

XLeast significant differences of means at $p<0.05$.

Among cultivars, mean AUDPC of seven cultivars were both significantly less than Van der Have 46177, while clean net root yield, recoverable sucrose and sucrose concentration of these seven cultivars were significantly higher than Van der Have 46177 (Table 2). Among the seven cultivars, Crystal R434, Beta 4797R, Crystal 820 and Van der Have 66561 were resistant whereas Beta 4818R, Hilleshog 2463Rz and Seedex Magnum were moderately resistant to Fusarium yellows in field conditions (Table 2). Van der Have 46177 responded as moderately susceptible in field conditions according to our criteria of categorization (Table 2). The resistant cultivars - Crystal R434, Beta 4797R, Crystal 820, and Van der Have 66561 - consistently had higher clean net root yield, recoverable sucrose yield and sucrose concentration than the moderately resistant cultivars - Beta 4818R, Hilleshog 2463Rz, and Seedex Magnum.

\section{Regression analysis}

Regression analysis by comparison of simple linear revealed that there was neither a significant difference in the intercept nor a significant difference in the slope between 2006 and 2007 in relating the AUDPC from greenhouse trials to those in the field trials. The estimated coefficient of correlation was $0.987(d f=14, p<0.01$ ) for AUDPC between greenhouse and field observations. When the most susceptible Van der Have 46177 was taken into account, there was a significant simple negative linear relationship of AUDPC with both the recoverable sucrose yield and the sucrose concentration among the eight cultivars grown in the fields. Comparison of the simple linear lines showed significant effects of seasons on the intercept, but no significant effects of seasons on the slope for both recoverable sucrose yield and sucrose concentration. Apparently, this reflected the fact that recoverable sucrose yield was significantly higher in 2006 than in 2007 whereas sucrose concentration was significantly higher in 2007 than in 2006. It also suggested that the rate of reduction per unit of presence in AUDPC was similar irrespective of large recoverable sucrose yields or high sucrose concentrations. The estimated coefficient of determination was $0.939(\mathrm{df}=13, \mathrm{p}<0.01)$ for relationship between recoverable sucrose yield and AUDPC and $0.894(\mathrm{df}=13, \mathrm{p}<0.01)$ for relationship between sucrose concentration and AUDPC.

\section{Discussion}

The greenhouse study showed that $F$. secorum was most virulent, followed by F. oxysporum, and then F. graminearum, on the most susceptible cultivar-Van der Have 46177. These results were consistent with those as shown in a pathogenicity study [15]. It was apparent that cultivars had varying levels of resistance to Fusarium yellows disease. Crystal R434, Beta 4797R, Van der Have 66561, and Crystal 820 were resistant to F. secorum and $F$. oxysporum and these cultivars were even not infected at all by $F$. graminearum. Beta 4818R, Seedex Magnum, and Hilleshog 2463Rz were moderately resistant to $F$. oxysporum and F. secorum, but just marginally prone to infection by $F$. graminearum. The AUDPC caused by F. graminearum was significantly lower than the AUDPC caused by $F$. oxysporum and $F$. secorum. Most of these cultivars showed similar responses to both the F. secorum and F. oxysporum.

Sugar beet cultivars showed similar response to Fusarium yellows in the field conditions with that in the greenhouse controlled conditions as indicated by the highly significant correlations in the corresponding observations between the two. Van der Have 46177 was a known susceptible cultivar Niehaus [20] and was used as a susceptible check in both the greenhouse 
and field studies. Van der Have 46177 had the highest AUDPC, and consequently the lowest clean net root yield and recoverable sucrose yield per hectare and sucrose concentration. The other seven cultivars had varying level of resistance to Fusarium yellows in the field. In general, AUDPC in the greenhouse was higher than in the field. In the greenhouse, the temperature was set and maintained at $27 \pm 2{ }^{\circ} \mathrm{C}$, which was optimum for Fusarium growth. In the field, the mean soil temperature for June to September was 22.4 and $21.5^{\circ} \mathrm{C}$ in 2006 and 2007, respectively. The mean soil temperature in June through August 2006 was relatively higher compared to June through August 2007. First symptoms were observed in the second week of June with higher soil temperature and more soil moisture. As the frequency of rainfall and high temperature increased, the disease severity also increased and was highest during the third week of July to the second week of August. Once the temperature started to decrease and infected leaves died, the infected plants appeared to be recovering by growing new leaves. Harveson \& Rush [13] also reported that more Fusarium root rot disease pressure was found in $30{ }^{\circ} \mathrm{C}$ temperature compared to $20^{\circ} \mathrm{C}$ in the greenhouse. The frequency of recovery of the Fusarium secorum was higher than the recovery of $F$. oxysporum, and was the lowest for $F$. graminearum from the field. In field conditions the pathogen would have competition with saprophytes. In the greenhouse, roots of sugar beet plants are usually damaged during washing which might become the entry point for the pathogen. In addition, plants in the greenhouse were in containers (21 cm deep) and roots could not develop and grow away from the pathogen whereas, roots in field conditions are able to quickly grow larger and deeper and therefore are more likely to escape from the pathogen. Furthermore, in the greenhouse, roots of inoculated plants were always in close proximity with the pathogen whereas in the field, existing pathogen distribution may not be uniform or the pathogen may not be at an infective stage.

In the field, resistant cultivars had higher clean net root yield and recoverable sucrose yield and sucrose concentration compared to moderately resistant cultivars and the susceptible check. From visual observations, resistant cultivars had more photosynthetic green leaf area, which resulted in larger clean net root yield and higher sucrose concentration in the root compared to moderately resistant or moderately susceptible cultivars. Larger clean net root yield and higher sucrose concentration in the root resulted in higher recoverable sucrose yield [27]. A strong negative relationship between AUDPC and sucrose concentration indicates that the Fusarium yellows had adverse impacts on beet quality and also reduced recoverable sucrose yield further since recoverable sucrose yield is the product of clean root yield and sucrose concentration after discounting for losses from sugar to molasses and other impurities.

Since the greenhouse and field results were congruently consistent, this will give a strong support and be an advantage in using greenhouse screening by bare-root inoculation to determine resistance level to the most pathogenic and virulent isolates of species causing Fusarium yellows. Seed companies usually need to test large number of accessions in their effort to develop resistant cultivars. It would be economical and efficient to use a greenhouse bioassay to screen accessions for resistance to Fusarium yellows so that only those with acceptable levels of resistance would be tested in field trials. Among the cultivars included within this research, Crystal R434, Beta 4797R, Van der Have 66561, and Crystal 820 were shown consistently resistant to Fusarium yellows both in greenhouse and field studies and can be therefore used as benchmarks by seed companies for screening sugar beet accessions resistant to Fusarium yellows disease.

\section{Acknowledgements}

This work was supported by North Dakota State Board of Agricultural Research and Education. Authors would like to thank Rishi Ram Burlakoti and Randy Nelson for their technical help. Special thanks to Crystal Beet Seed, Betaseed, Ses Vander Have and Syngenta Seeds for providing seeds with different levels of susceptibility to Fusaium.

\section{References}

1. Stewart D (1931) Sugar-beet yellows caused by Fusarium conglutinans var betae. Phytopathology 21: 59-70.

2. Snyder WC, Hansen HN (1940) The species concept in Fusarium. Am J Bot 27(2): 64-67.

3. Larson RL, Hill AL, Fenwick A, Kniss AR, Hanson LE, et al. (2006) Influence of glyphosate on Rhizoctonia and Fusarium root rot in sugar beet. Pest Manag Sci 62(12): 1182-1192.

4. Anonymous (2011) Ag Note 544. Variety selection critical connection to disease management. American Crystal Sugar Company.

5. Bockstahler HW (1940) Resistance to Fusarium yellows in sugarbeets. In: Proceedings of the Am. Society of Sugarbeet technologists 2, Colorado, USA, pp. 191-198.

6. Hanson LE (2006a) Fusarium yellowing of sugar beet caused by Fusarium graminearum from Minnesota and Wyoming. Plan Dis 90: 686.

7. Hanson LE (2006b) First report of Fusarium yellows of sugarbeet caused by Fusarium oxysporum in Michigan. Plant Dis 90(12): 1554.

8. Bosch U, Mirocha CJ (1992) Toxin production of Fusarium species from sugar beets and natural occurrence of zearalenone in beets and beet fibers. Appl Environ Microbiol 58(10): 3233-3239.

9. Windels CE, Brantner JR, Bradley CA, Khan MFR (2005) First report of Fusarium oxysporum causing yellows on sugar beet in the Red River Valley of Minnesota and North Dakota. Plant Dis 89(3): 341.

10. Rush CM, Martyn RD (1991) Variation in sugarbeet susceptibility to isolates of Fusarium oxysporum f. sp. betae from Texas and Oregon. (Abstr.) Phytopathology 81: 1200.

11. Hanson LE, Hill AL (2004) Fusarium species causing Fusarium yellows of sugarbeet. J Sugar beet Res 41: 163-178.

12. Khan MFR, Bradley CA, Windels CE (2003) Fusarium yellows of sugarbeet. Univ Minn Ext Serv and North Dakota State Univ. Ext Serv pp. 1247.

13. Harveson RM, Rush CM (1998) Characterization of Fusarium root rot isolates from sugarbeet by growth and virulence at different temperatures and irrigation regimes. Plant Dis 82(9): 1039-1042. 
14. Asher MJC, Hanson LE (2006) Fungal and Bacterial diseases. In: Draycott AP (Ed.), World Agriculture Series Sugarbeet. Blackwell Publishing Ltd., Oxford, UK, pp. 286-309.

15. Burlakoti P, Rivera VV, Secor GA, Qi A, del Rio LE, et al. (2012) Comparative pathogenicity and virulence of Fusarium species on sugar beet. Plant Dis 96: 1291-1296.

16. Secor GA, Rivera-Varas V, Christ DS, Mathew FM, Khan MFR, et al. (2014) Characterization of Fusarium secorum, a new species causing Fusarium yellowing decline of sugar beet in north central USA. Fungal Biol 118(9-10): 764-775.

17. Biancardi E (2005) Resistance to parasites. In: Biancardi E, Campbell LG, Skaracis GN, De Biaggi M (Eds.), Genetics and breeding of sugarbeet. Science Publishers, Inc. Enfield, New Hampshire, USA, pp. 74-116.

18. Khan MFR (2008) Successful collaboration between industry and universities in the US beet sugar industry. Int Sugar J 110: 218-220.

19. Niehaus WS (2006) Results of American Crystal's 2005 official coded variety trials. 2005 Sugarbeet Res Ext Rep 36: 331-333.

20. Panella L, Lewellen RT (2005) Objectives of sugarbeet breeding. In: Biancardi E, Campbell LG, Skaracis N, de Biaggi M (Eds.) Genetics and Breeding of Sugarbeet, Science Publishers, Inc., New Hampshire, USA, pp. 53-167.
21. Hanson LE, Hill AL, Jacobsen BJ, Panella L (2009) Response of sugarbeet lines to isolates of Fusarium oxysporum f. sp. betae from the United States. Journal of Sugar Beet Research 46: 11-26.

22. Rivera V, Rengifo J, Khan M, Geiser D, Mansfield M, et al. (2008) First report of a novel Fusarium species causing yellowing decline of sugar beet in Minnesota. Plant Dis 92(11): 1589.

23. Burlakoti P, Rivera VV, Burlakoti RR, Nelson R, Adhikari TB, et al. (2010) Baseline sensitivity of Fusarium species associated with Fusarium diseases to metconazole, triticonazole, and thiabendazole fungicides. J Sugar beet Res 47(1-2): 23-34.

24. Khan M (2006) Sugarbeet Production Guide. North Dakota State Univ \& Univ Minnesota Coop Ext Serv, Fargo, ND.

25. Campbell CL, Madden LV (2006) Introduction to Plant Disease Epidemiology. John Wiley and Sons, New York, pp. 560.

26. Gomez KA, Gomez AA (1984) Statistical Procedures for Agricultural Research. (2 ${ }^{\text {nd }}$ edn), John-Wiley \& Sons, New York, p. 680.

27. Elliott MC, Weston GD (1993) Biology and physiology of the sugar beet plant. In: Cooke DA, Scott RK (Eds.), The Sugar Beet Crop: Science into practice. Chapman and Hall, London, UK, pp. 37-66.

\section{Your next submission with Juniper Publishers will reach you the below assets}

- Quality Editorial service

- Swift Peer Review

- Reprints availability

- E-prints Service

- Manuscript Podcast for convenient understanding

- Global attainment for your research

- Manuscript accessibility in different formats

( Pdf, E-pub, Full Text, Audio)

- Unceasing customer service

Track the below URL for one-step submission https://juniperpublishers.com/online-submission.php 